\title{
Sustainable Development of Agriculture: Modeling of Strategic Management in Transition Countries
}

\author{
${ }^{*}$ Reznik Nadiia, ${ }^{* *}$ Ostapchuk Anatoliy, ${ }^{* *}$ Koshchenko Kateryna
}

* Department of stock exchange activity and trade, National University of Life and Environmental Science of Ukraine, Ukraine

* * Faculty of Agricultural Management, National University of Life and Environmental Science of Ukraine, Ukraine

** * Departement of Management, National University of Life and Environmental Science of Ukraine, Ukraine

JEL Classification: Q00, Q19

\section{ABSTRACT}

The aim of the paper is to provide a new view on the practice of concept development and the implementation of strategic management in the context of the return of some agricultural enterprises to the principles of a planned economy. Lack of research on this direction makes topic of the paper is promising for consideration. This paper provides evidence-based explanations of the problem. As a result of research followed steps were made: the components of the algorithm of actions for the main executor of the strategy are singled out; the scheme of realization of strategic planning is offered; a list of predictive calculations has been compiled, which underlie modeling of the main directions of the industry development and are necessary for forecasting the development of agriculture; the criteria and principles of sustainable regional development have been determined and a scheme for its implementation has been developed.

Keywords:

strategic management, agriculture, sustainable development, countries in transition, modeling, strategic planning 


\section{INTRODUCTION}

Unsatisfactory economic situation in the agricultural complex in the transition countries is caused by the lack of deep economic knowledge and experience of strategic thinking among the heads of management. Consequently, the very need to adapt the enterprise to the constantly changing conditions of the external environment is obvious, but how to manage it in a transitional economy and sometimes a recessive strategy is not fully understood, which predetermines the relevance of the research topic in this direction. The purpose of the study is to provide a new view on the practice of concept development and the implementation of strategic management in the context of the return of some agricultural enterprises to the principles of a planned economy.

\section{IITFRATURF RFVIFW}

There are no fundamental researches in the area of entrepreneurial management of agricultural enterprises. Despite the fact that there are publications a lot of authors on the problems of strategic management, crisis management, the theory of modern entrepreneurship and business management of the company, there is an urgent need to develop a toolkit for strategic management of sustainable development of agricultural organizations. Entrepreneurship is defined by a complex and diverse system of factors in a competitive environment, among which a key role is played by the process of forming goals and choosing a development strategy.

A significant contribution to the research of strategic management of planning belongs to such scientists as Ansoff H.I.(1965), Porter M. E. (1985), Benson T. (1996), David E.R. (1999) and others.
Risks of agricultural enterprises were studied by the Bard S. (2000), Borges J.A.R., Machado J.A.D. (2012), Rusnakova M. (2016). Problems of management of agricultural enterprises are reflected in researches of Chandler A.D. Jr. (1962), Andreff Wladimir (2000), Monks A. (2007), Vachal J., Vochozka M. et al. (2013), Reznik N. (2016). Theoretical backgrounds, foreign experience and possible external problems were reviewed by the Reznik N. (2008), Kvasha S. (2008), Nyaupane N. P., Gillespie J. M. (2010), McNamara C. (2015), Davis John, Legg Wilfrid, Blandford David (2015).

\section{IMETHODS}

During researching different methods were used so as induction, deduction, comparative analysis and theoretical generalization. The main provisions of the enterprises of agrarian sector in Ukraine were researched and its experience in the implementation of strategic management.

\section{RESEARCH FINDINGS}

Deepening market relations in the economy and trying of some enterprises to use principles of planned economy require a new look at the practice of developing concepts and managing the implementation of the strategic aims of the industry.

Practical embodiment of the strategy means the implementation of the strategic plan in specific managerial decisions that ensure the achievement of the aims by individual agricultural producers, municipalities, regions, country. Both the process of developing a strategy and its implementation are the work of the entire management team (the appropriate level), and not just the head level. The process of implementation of the strategy usually affects every element of the organizational structure of management, and in this sense 
all managers are executing the strategy within their authority and responsibility, and the remaining employees are participants in this process.

Communication is one of the factors that contribute successful implementation of the strategy. The management should so clearly and convincingly formulate the need to make organizational changes, so that everyone independent on the position felt their responsibility for implementing the strategy and achieving the set goals. When strategic goals are achieved, financial and production tasks are performed, it can be assumed that the implementation process was successful.

Approaches to the implementation of the strategy are corresponding to each specific situation, but at the same time, there are certain basic requirements that must be fulfilled independently of the object of management and include the following:

- creation of an organizational management structure that is capable to successfully implement strategic objectives;

- review of budgets in order to allocate sufficient resources to those activities that define strategic success;

- establishment of appropriate strategic courses and procedures;

- introduction of proven, best practices and technology to ensure continued development and improvement;

- installation (installation, construction) of supporting systems that enable management personnel to successfully carry out their strategic role all time;

- combining the reward and motivation system with the implementation of the strategy at a high level and achievement the set goals; creating a business environment and a corporate culture that support the conditions for implementation the strategy;

- supporting internal competitiveness (leadership) that is necessary for the implementation of the strategy, as well as its improvement in the implementation process.

These management tasks periodically arise in the process of implementation of strategy independently on the specific situation and define the priorities for making managerial decisions by the executors of the strategy (Figure 1).

Some of these tasks are usually not performed, being less significant or requiring more time to solve them, which depends on financial and competitive opportunities; on the nature and extent of ongoing strategic changes; from the conditions for creating an appropriate competitive advantage; from the strength of established models of behavior that need to be changed; from whether the market participant has weaknesses that need to be overcome or whether it is necessary to raise the level of competence in any areas; from established personal and organizational connections; from possible pressure on performers in order to obtain quick results and from many other factors that define the current functioning and development strategy of the management object.

In developing an action plan the governing body of the strategy must proceed from the definition of what needs to be done differently and better to successfully implement the strategy, and then to define how to implement the required internal transformations as quickly as necessary or possible. First, the actions of the strategy 
The main questions for the executor of the strategy: what to do now, and what to
postpone for later? What requires a lot of time and personal attention? What can be delegated to others?

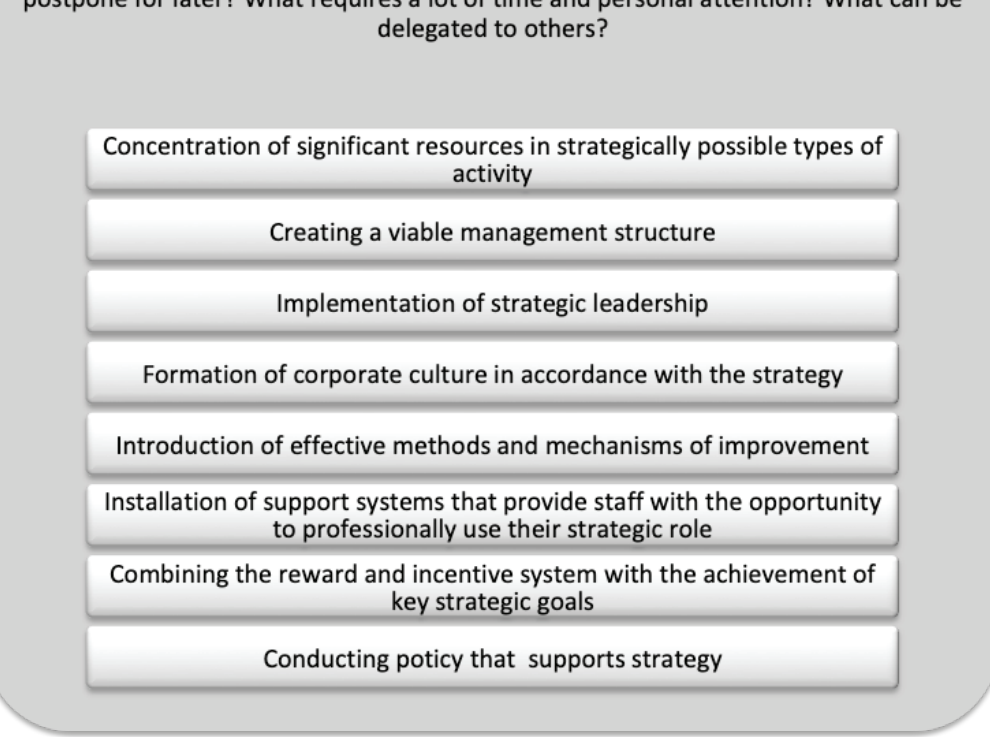

Figure 1. The main managerial decisions in the implementation process of strategy

organizer should be aimed at assessing how the entity conducts activities that constitute priorities and identifies leadership in strategy management in order to ensure better implementation of strategies. For this, it is necessary to create a number of such "correspondences". The potential opportunities of management personnel have to be appropriate for requirements of the strategy, especially if the chosen strategy is based on the formation of a competitive advantage due to the level of competence of managers. Resources should be allocated in such a way as to provide production structures in sufficient volume that is necessary for the effective implementation of its strategic role - creating priorities in competition. It is necessary that the system of motivation that exists in the object of management, its policy, information system and production practice contribute to the implementation of the strategy and not play passive roles. It is also important that the style of functioning of the management system create and develop the working environment and corporate culture that supports the strategy.

One of the constructive or destructive components of effective implementation of the strategy is the level of management of the process, that is, how well the management system functions. Senior managers can play an active, visible role or distance themselves to secondary positions. They can make decisions authoritatively or on the basis of consensus. They can delegate authority to a greater or lesser extent to the lower levels of leadership, to be personally involved in the details of implementation of the strategy or to be aside and instruct others. They can act quickly (implement initiatives at once on many directions) or carefully (focus on gradual progress for a long time).

Guidelines for the implementation of the strategy depends on various factors, among which can be highlight: 
1. experience and knowledge of business by managers;

2. whether they are novices or veterans in the field;

3. personal corporate relationships;

4. their experience in diagnosing and solving problems, as well as skills in administration and interpersonal relations;

5. power authority, which they will possess;

6. the preferred style of leadership;

7. their vision of the role they must play in order to ensure the implementation of the strategy.

The executor of the strategy, which is at the highest level of management, should act according algorithm of actions, that includes, mainly, the following:

- delegation of authority to subordinates (transfer of functions to conduct changes in the process);

- reaching agreement in actions and putting forward their strong supporters in positions that will provide them to move the implementation process of the strategy forward in key areas;

- development of incentives for employees and creation of opportunities for implementation of the strategy;

- developing a system to assess progress and its boundaries;

- recognition of merit and rewarding those who have achieved certain results;

- redistribution of resources;

- personal leadership by the process of strategic change.

The first step is a detailed strategic analysis that connects the prospects and goals for strategy development (Figure 2). The next step is to set up two groups of tasks: short-term, designed for the current implementation, and strategic, for the implementation of which programs are developed. Current plans and budgets are focused on routine activities that are directed at ensuring current efficiency, while strategic programs lay the foundations for the sustainability of future development. But strategic programs poorly act into the system of execution of current operations and requires a separate execution system which is built on project management.

A distinctive feature of the projects is its orientation on achievement of strategic goals not on day-to-day activities. Projects are created on a temporary rather than an constant basis (the principle of indicativeness). The time iteration differs from the annual period in the management of projects. The allocation of targeted resources for the implementation of the strategy (separate budgets of strategic programs) is the main condition for its implementation and an effective management mechanism. Thus, the common problem is to provide a balance between the strategic and current orientation of the activity of the management subject, between current and future problems, and it is recommended to organize a dual management system for this purpose: current problems and strategic tasks, while solving current tasks should ensure implementation of long-term goals.

In this regard, it should be noted that there is another effective tool widely used to implement plans. There are procedures or regulations.

Procedures are defined as a system of successive steps or techniques that describe in detail the process of implementation of individual tasks or works. 


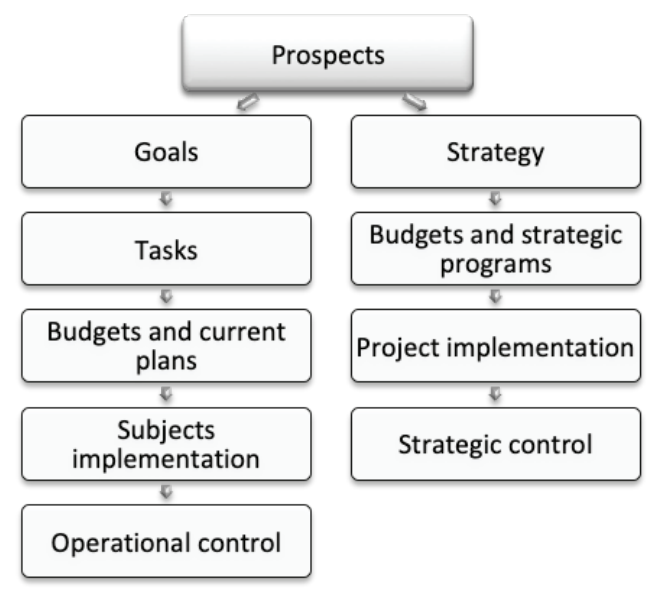

Figure 2. Scheme of the implementation of strategic planning Source: Ansoff H.I. (1965)

The procedures guarantee that the daily operations will be coordinated in time, that is, the nature of the activity will remain constant, in accordance with the established production technology. It is the procedures that provide all units and personnel at the appropriate places will follow the same style of business activity. At the same time, the complexity of real life needs the synthesis of a planned approach and the current adjustment of plans. From this follows the need to coordinate planning with marketing and control in order to constantly harmonize production and sales parameters in accordance with changes in market conditions. At the same time, the attention of strategic managers should be directed to the intensification of the influence which is aimed at activating the formation of market demand.

The final part of the strategic management model is the monitoring of the implementation of the strategic plan. It is necessary to identify problems before they manifest themselves and create a threat to the fulfillment of the set goals. In management theory, control is viewed as a five-step process, consisting of the following actions:
- Definition of parameters, in other words, the spheres of control, which should to be evaluated.

- The development of standards or the precise definition of goals (control figures), which must be achieved in a specified period. Accordingly, the standards that are used to assess the implementation of the strategy are the details of strategic objectives. Naturally, standards for quantitatively measured parameters (for example, sales volume, profit) are more easily established. In the control system, standards are developed not only to evaluate the final, but also intermediate results. At this stage, the values of permissible deviations from the standards are also established.

- Evaluation of the operation results for a specified period.

- Comparison of real results with established standards. At this stage, it is also decided whether the deviations from the established standards are acceptable.

- Development of corrective actions in the event that deviations are more than permissible, that is, the causes of deviations and ways of its elimination are revealed. Note that the monitoring 
system may indicate the need to review the plans and standards (for example, the objectives may be too optimistic).

Three types of control are distinguished in the economic management system: strategic (operational results over a year), tactical (6-12 months), operational (up to 6 months). Hierarchy of strategy and hierarchy of control also exist. Mainly strategic control is conducted for the federal and regional levels, where the main focus is on maintaining a balance between different sectors of the economy. Tactical control prevails at the level of municipal formation, where identifies the problems of competitive positions of various types of business. In the process of tactical control, as a rule, the levels of costs and the shares of individual commodity producers in the territorial markets are tracked. Functional level is characterized by tactical but mainly operational control, in which implementation indicators are monitoring daily or weekly that allow, for example, real-time monitoring of the number of made orders, the number of complaints and other current quantitative parameters. Budgets are an important tool for monitoring strategic programs, as well as the results of activities of specific management objects or projects.

The modern methods that are used to justify the strategy of agriculture and its practical implementation require further development. Contradictions arise even when defining the strategy for the development of the industry, since there is no adapted methodological apparatus for forecasting. Proceeding from this, when developing forecasts for the development of rural areas and the leading industry, it is expedient to use general methodological approaches.
If trend models are used in the compilation of economic forecasts, it should keep in mind that the analysis of trend series of production, trade, consumption of agricultural products and foodstuffs leads to a considerable dispersion of forecast indicators and high dispersion. This requires structuring a sample of actual demand and supply of agricultural food products.

Step-by-step actualization of the real data may lead to a restriction of the volume of standardization that is necessary to define the economic strategy with use of trend models. In this case, when developing the forecasts of supply and demand based on these models, it can be applied the method of multiplication of estimates, the essence of which is the breakdown (fragmentation) of the initial time interval into random intervals by points uniformly distributed on it. This procedure is repeated many times and at each stage the coefficients of the approximating polynomial are calculated by the method of least squares.

All known developments of algorithms for calculating forecast indicators of supply and demand of agricultural products and food can be divided into two types of models. There are general and partial equilibrium. The principal difference between them is that general equilibrium models consider all product markets, as well as labor and capital markets; partial equilibrium - only the balance between supply and demand for specific types of goods.

Management of long-term forecasting in the strategy of agricultural development can be successful only if, firstly, it relies on an objective prediction of economic dynamics, that is, on the scientifically grounded definition of general trends of 
economic development in the designated perspective; secondly, the approved methods of quantitative assessment of sound trends are used, taking into account the totality of problems and disadvantages of the regulatory framework at the regional level, as well as the specifics of the trends in the development of industry in the region.

To develop a forecast for the development of agriculture in the region for a period, for example, until 2020 , it is necessary to clarify:

- what products and in what proportions will the customer demand change;

- what indicators of productivity (harvests, yields, growth of live weight, etc.) in the forecasted perspective in different territories can be calculated;

- what are the prospects for involving in the economic turnover by 2020 of land, material, labor and financial resources;

- what are the directions for rational use of the resources of enterprises and the region as a whole, so that conceptually established reference points can be achieved with minimal costs.

All these questions can be answered in the course of modeling the main directions of the industry development, based on a large array of information in the course of pre-planned calculations. They provide an opportunity to define the prospects for individual economic events, as well as the overall dynamics of agricultural production processes. The program for the development of agriculture, which is compiled on the basis of forecast calculations, is the main tool for strategic management of the industry.

The development of the strategic plan for agriculture and management of its implementation process execute the main goal - providing the sustainability of the industry development and improving the social and economic situation in rural areas.

The content of the concept of "sustainable development of territories" is mainly considered in relation to global or regional systems and is defined as a strategy of survival and development that is based on economic growth, which allows saving the environment for present and future generations. The most acceptable model of sustainable development can be implemented primarily at the regional level, where the inertia of the processes is lower than at the level of rural municipalities, as well as the ability to make quick managerial decisions and to use resources. The connection of economic, political and other managerial decisions with social processes at the level of the region is revealed directly. Regulatory activity of the state in the economy should be, at the same time, the guarantor of sustainability in the social system.

The most acceptable understanding of the stable development of the region is a functioning of a self-organizing system that is aimed at harmonizing the life activity of the local community and it's environmentally balanced development with the aim of improving the quality of life of the population and having certain criteria and principles (Table 1).

The process of the strategic development is presented in Figure 3. Thus, the sustainable development of the agricultural sector of the economy is the ability of the subjects of agriculture at various levels to dynamically maintain optimal proportions, reproduction factors and provide the necessary rates of its development in conditions of economic risk. At the same time, the natural, climatic 
Table 1. Criteria and principles of sustainable regional development as a socio-ecological and economic system

\begin{tabular}{ll}
\hline Criteria & Principles \\
\hline Adaptability & Rational nature management \\
\hline Optimality & Optimal structure of production and consumption \\
\hline Provision & $\begin{array}{l}\text { Satisfaction of the vital needs of society at present and in the } \\
\text { future }\end{array}$ \\
\hline Ecological compatibility & $\begin{array}{l}\text { Ecological preservation of existing ecosystems and restoration } \\
\text { of damaged ecosystems }\end{array}$ \\
\hline Democracy & Transparency of economic activity of the region \\
\hline Systematic & Systematic approach to the economic development of the region \\
\hline Source: compiled by author. &
\end{tabular}

and production potential of agriculture can be effectively implemented on the basis of an optimal combination of production factors, resource-saving technologies and improving the forms of organization of production, which cannot be achieved without strategic planning and management of its implementation processes.

Development of quantitative parameters (threshold values) of the state of the economy to justify a development strategy is an objective necessity that allows creating a real tool for its evaluation and a base for long-term planning and management.

The strategic directions of the state economic policy in the agricultural complex should be oriented towards the following goals:

- provision of sustainable rates of economic growth and scientific and technical progress, increasing the competitiveness of products in the domestic and foreign markets, effective integration into foreign economic relations;

- achievement of the quality of life of the population according to the standards of economically developed countries, including in the areas of education, health, cleanliness of the environment, ensuring economic rights and freedoms of citizens.

A steady increase in the incomes of the agricultural complex as whole, agricultural producers, processing enterprises and workers is the main criteria for the successful and progressive development, due to which the growth of state income and the investment opportunities of commodity producers and the state will be ensured. At the same time, sustainable development of the agricultural complex should correspond to the strategic interests of the population. The process itself is a coordinated action in space and time of four basic conditions:

- due to the influence of global market fluctuations, the dynamics of international debt, the rate of country and other external conditions;

macroeconomicasatotality of procedural measures to limit the economic interference of state organizations in the production and economic activities of economic entities, expand the boundaries of economic freedom, tightly regulated through inflation and the interest rate, commodity interventions, income of the population; 


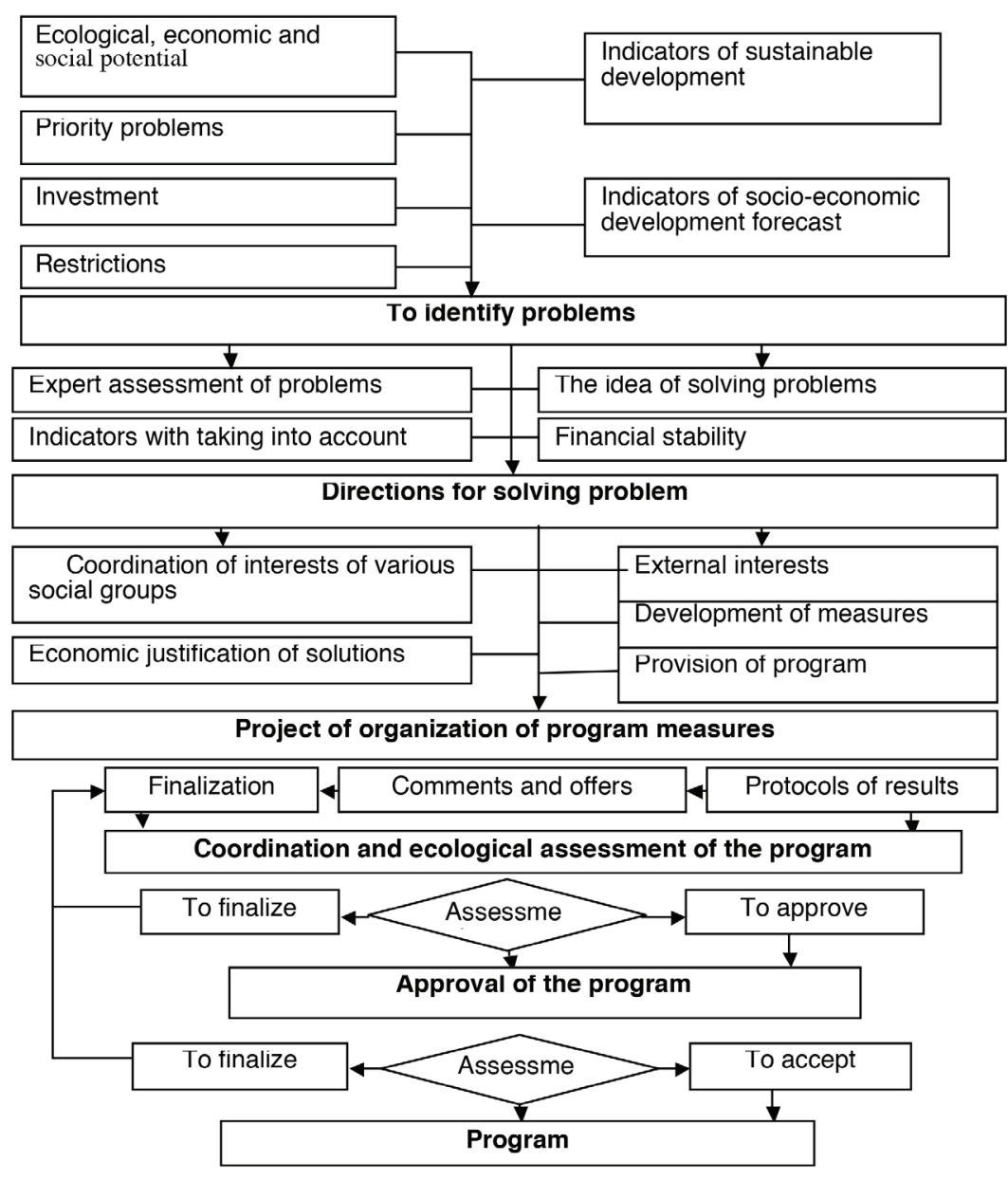

Figure 3. The development of the Sustainable Development Program Source: compiled by author.

- regional (territorial), that have influence on the economic development with a totality of organizational and economic decisions which increase the entrepreneurial activity of economic entities;

- microeconomic (local) as a totality of flexible organizational, economic, technical and technological changes in production itself, ensuring synchronization of production interaction (biosystems) with nature, the system of risks, including economic and natural which represent a system of market and competitive self-organization of reproduction.
One should also pay attention to the fact that sustainable development, as a rule, carries not only the solving problems, but also the potential socio-economic conflict. Removing some contradictions, it aggravates others. Economic growth is accompanied by a structural breakdown, the growth of differentiation and tension between individual segments of the economy as a result of the redistribution of resources from inefficiently developing sectors, social groups and territories into an intensively developing way of life.

Thus, the sustainable development of the agricultural complex is an area of economic relations that continuously 
provides rational proportionality between the factors of agricultural production and the necessary rates of its development in conditions of economic risk and the variability of the external conditions of functioning to satisfy the population's needs for food and consumer goods that are produced from agricultural raw materials.

One of the main conditions for the strategy of sustainable economic and social development is the solving the social problems of the rural population and the development of the village. Active social policy in the countryside should be conducted with taking into account the experience of development of rural areas in the world community. It should be viewed as a holistic process of recreation of human connections, provision of conditions for the effective development of the economy, improvement of the quality and prestige of life in the countryside.

Therefore, the real sector of the economy as a basis for the welfare of the population requires special attention from the side of the management bodies of all levels. The district government in economically developed countries is faced the following tasks:

- formation of an optimal combination of state regulation and market regulators of economic development;

- coordination of branch strategies and strategies for the development of economic entities with the strategy of the municipality;

- coordination of plans for civil and industrial land use with plans for the development of housing and communal services of the municipal formation;

- provision of the competitiveness of the municipal entity in the international market for goods, services and resources as the basis for a high quality of life for the population.

The successful solution of these tasks depends on the ability of the authorities and the business community of the territory to find principles, forms and methods for effective interaction.

Business needs from the government, first of all, stability and predictability, which allow plan actions for the future. And from this point of view, the region also needs this predictability as a set of economic entities, limited territorially and having a single budget.

Therefore, the management bodies of the territory and its agricultural complex are called upon to study sales markets; define the strategy for the development of the territory, coordinating it with the regional strategy for the development of the industry; to conduct strategic planning as a basis for the planned management of the economy for each economic entity, which makes it possible to define, on the one side, the need for budgetary support for noncommodity types of products, which are necessary for the region, on the other side, the expediency of diversification as a means of replacing goods that are withdrawn from commodity production.

Thus, the key idea and the main directions of the anti-crisis strategy for the development of agriculture presuppose, first of all:

- approval of a strategic planning system which is able to identify promising areas of economic growth, and directs the activities of state management institutions to implement them;

- formation of channels for financing 
projects of the creation and development of production and technological complexes in the village of a new technological order and spheres of use (consumption) of its products;

- adjustment of the agrarian macroeconomic policy, which provides favorable conditions for innovation activity.

The system of strategic planning and management of its implementation should include: selection of priorities for technical and economic development, tools and mechanisms for its implementation, institutions for organizing relevant activities and methods for monitoring the achievement of the required results.

\section{CONCLUSION}

Modern strategic planning is not a rigid system of planned centralized management, but an integral complex of flexible regulatory influences of an organizational, legal, methodological and informational nature. It allows to provide interested, free and constructive cooperation of federal, regional and local authorities, as well as economic entities and local communities in the development and implementation of forecast and planning documents that define the development prospects of the country and its territories.

A strategy is understood as a general program of actions that identifies the priorities of problems and resources to achieve the main goal, which formulates the main ways of its implementation in such a way that the enterprise receives a certain direction of development.

Strategic decisions are those actions, the implementation of which lead to long-term consequences and are an integral function of the management entity of any enterprise. Proceeding from this, the strategic management acts as the process of strategic decision making and implementation, the central link of which is the strategic choice of the enterprise, based on the comparison of its own resource potential with the opportunities and threats of the external environment in which it operates.

Thus, strategic decisions are management decisions that:

- are oriented to the future and lay the foundation for the operational management decisions;

- involve significant uncertainty because take into account that uncontrolled external factors have influence on the enterprise;

- are associated with the involvement of significant resources and can have extremely serious, long-term consequences for the enterprise.

At the same time, strategic management is defined as a complex of not only management decisions for the long-term development of a firm, but also concrete actions that ensure a rapid response to changes in the external environment, which can lead to necessity of strategic maneuver, the revision of goals and the adjustment of the general direction of development.

Strategic decisions about the future goals of the enterprise and the ways of its achievement are, in essence, a strategic planning process, which results in a system of plans, activities for implementation of planned decisions and monitoring the implementation of plans. The planning process itself is a closed cycle with a direct communication (from the development of 
the strategy to the definition of operational plans, implementation and monitoring) and the feedback (the account of the results of implementation and adjustment of the plan).

The economic essence of strategic planning lies in the ideal representation of interested parties about the future state of the management object and its external environment, which most fully corresponds to their value orientations and is an expression of the corporate interests of the subject.

Implementation of strategic decisions is conducted by management, which is the organization and management of entrepreneurial activities in order to obtain sufficient profits, reduce production and circulation costs, strengthen the entrepreneurial market positions and reduce the risk which is associated with operations in the market, labor conflicts and other organizational and management issues. Strategic management provides the rationality and choice of promising goals for the development of the enterprise and increasing its competitiveness, its consolidation in long-term plans, the development of targeted programs that ensure achievement of the intended goals. Like any management process, strategic management necessarily includes analysis, planning (choice) and implementation of the decision.
The main stages of strategic management show that this is a comprehensive management system which is based on forecast of the external environment and developing ways to adapt the enterprise to its changes. This system helps the head of the enterprise to anticipate the business development trends, to monitor and understand the influence of the external environment, define the strategic choice and implement the strategy.

Sustainable development of agriculture is an area of economic relations that continuously ensures rational proportionality between the factors of agrarian production and the necessary rates of its development in conditions of economic risk and the variability of the external conditions of functioning to satisfy the needs of population for food and consumer goods that are produced from agricultural raw materials.

The peculiarity of business planning in modern conditions is the design technologies of management of branches and processes in agriculture, which should be reflected in the plans. The transition to innovative economic models, which are the basis for increase of the competitiveness of agrarian products in the context of globalization of the economy, requires large investments in the industry. 


\section{RFFFRFNCFS}

Leedy, P. D., and J. E. Omrod. 2005. Practical Research: Planning and Design (8th ed.). Upper Saddle River, New Jersey: Merril Prentice Hall.

Perry , C., D. Carson, and A. Gilmore. 2003. Joining conversation: Writing for EJM's editors, reviewers and readers requires planning, care and persistence. European Journal of Marketing 37 (5/6): 653-55\%.

Summers, J. O. 2001. Guideline for conducing research and publishing in marketing: From conceptualization through the review process. Journal of the Academy of Marketing Science 29 (4): 405-415.

Feldman, D. C. 2004. The devil is in the details: Converting good research into publishable articles. Journal of Management 30 (1): 1-6.

Ansoff H.I. 1965. Corporate Strategy. New York: McGraw-Hill.

Porter M. E. 1985. Competitive advantage: Creating and sustaining superior performance. New York: The Free Press.

Benson T. 1996. Agricultural and environmental research in small countries: Innovative approaches to strategic planning. New York: John Wiley \&e Sons.

David E.R. 1999. Strategic Management Concepts (7th ed.). New Jersey: Prentice Hall.

Bard S. 2000. Developing a scale for assessing risk attitudes of agricultural decision makers. The International Food and Agribusiness Management Review 3: 9-25. https://doi. org/10.1016/S1096-7508(00)00024-0

Borges J.A.R., Machado J.A.D. 2012. Risks and risk management mechanisms: An analysis of the perceptions of producers of agricultural commodities. Interdisciplinary Journal of Research in Business, 2: 27-39.

Rusnakova M. 2016. Commodity price risk management using option strategies. Agricultural Economics (Zemědělská ekonomika), 61: 149-157 https://doi.org/10.17221/101/2014AGRICECON

Chandler A.D. Jr. 1962. Strategy and Structure: Chapters in the History of Industrial Enterprise. Cambridge: Cambridge MIT Press.

Andreff Wladimir 2000. Corporate governance and residual state property (two qualitative shortcomings of privatization in transition countries). Prague Economic Papers, 2000. https://doi.org/10.18267/j.pep.61

Monks A. 200\%. Corporate Governance (3th ed.). London: Blackwell Publishing.

Vachal J., Vochozka M. et al. 2013. Business Management. Prague: Grada Publishing.

Reznik N. 2016. Entrepreneurial firm: organizational aspect. Ukraine, Kyiv: Publishing of Kyiv International University.

Kvasha S. 2008. Vplyv svitovoyi finansovoyi kryzy na rozvytok ahrarnoho sektoru vitchyznyanoyi ekonomiky. [The influence of the global financial crisis on the development of the agricultural sector of the national economy], Economy of AIC 8: 60-6\%.

Reznik N. 2008. Mizhnarodna praktyka investuvannya v ahrarnomu sektori. [International practice of investing in the agrarian sector], Economy of AIC 12: 65-6\%.

Nyaupane N. P., Gillespie J. M. 2010. Louisiana crawfish farmer adoption of best management practices. Journal of Soil and Water Conservation 66: 61-70. https://doi.org/10.2489/ jswc.66.1.61

McNamara C. 2015. Historical and Contemporary Theories of Management. Available at http:// managementhelp.org/management/theories.htm

Davis John, Legg Wilfrid, Blandford David 2015. Climate Change and Agriculture. EuroChoices 14(1): 3. https://doi.org/10.1111/1746-692X.12074 